\title{
Application of Recycled Structural Concrete to Replace of Coarse Aggregate under the Building Control Laws and Construction Standards
}

\author{
Punkorn Cheewawutwatanawit ${ }^{1}$ \\ *1 A Ph.D. Student in the Engineering Law and Inspection \\ Program, Ramkhamhaeng University; \\ ORCID: 0000-0003-4650-7731.
}

\author{
Asst. Prof. Dr. Waranon Kongsong ${ }^{2}$ \\ Asst. Prof. Dr. Krisda Bisalyaputra ${ }^{2}$ \\ ${ }^{*}$ Assistant Professor in the Engineering Law and \\ Inspection Program, \\ Faculty of Engineering, Ramkhamhaeng University; \\ ORCID 0000-0003-2651-8476.
}

\author{
Assoc. Prof. Dr. Seree Tuprakay ${ }^{3}$ \\ *3 Associate Professor in the Engineering Law and \\ Inspection Program, Faculty of Engineering, \\ Ramkhamhaeng University.
}

\author{
Dr. Sathian Charoenrian ${ }^{4}$ \\ Dr. Boontham Harnphanich ${ }^{4}$ \\ ${ }^{*}$ Special Lecturer in the Engineering Law and Inspection \\ Program, Faculty of Engineering, \\ Ramkhamhaeng University.
}

\author{
Dr. Chaiwat Pooworakulchai ${ }^{5}$ \\ *5 Lecturer in the Engineering Law and Inspection Program, \\ Faculty of Engineering, Ramkhamhaeng University; \\ ORCID: 0000-0002-4005-253X
}

\begin{abstract}
The purpose of this research is to study application on the structural concrete, which destroyed, replace of coarse aggregate under the Building Control Law and the Construction Standards. This research uses a mixed research methods approach to sampling 480 concrete strength examples. To compare the compressive strength of recycled coarse aggregate concrete replaces $100 \%$ natural rock. Including the curing test which compared among air curing and chemical compound curing. After that conducting, the instruments by interviewing the concrete professionals who are civil engineers directly. That would like to know the opinion about bringing recycled aggregates to replace natural coarse aggregates for using the concrete. Formulate the prediction equation of concrete strength came from recycled concrete aggregates with the different strengths replace of natural coarse aggregates.
\end{abstract}

The results show that a compound curing has the recycled concrete strength development higher than an air curing. Also, the concrete mixed design can use for having the concrete strength higher than the law stated, including the concrete experts' opinion about the use of structural concrete, which destroyed to replace coarse aggregate under the Building Control Law and Construction Standards. In the framework of the Building Control Law and Concrete standard. Improvement can divide into two parts; (1) the original concrete strength according to the Ministerial regulation was a minimum strength of designing a concrete building. The suggestion is to find the recycled aggregate concrete strength that is usable, and (2) the five aggregates recycle concrete standard are mixtures proportion, mixture selection criteria, evaluation criteria, mix method technique, and the recycled aggregate concrete test. Using the structural concrete, which destroyed to replace coarse aggregate it can reduce concrete waste pollution that is hardly disposable. Decrease the environmental impact by having the value-added on concrete waste replacing the natural coarse aggregates.
Therefore, the application on structural concrete, which destroyed replacing coarse aggregates on the Building Control Law and Construction Standard is significant. That is beneficial in both civil engineering and environmental engineering.

Keywords: Recycled Concrete, Recycled Structure Reliablity, Concrete, Concrete Strength, Compressive Strength, Recycled Coarse Aggregate, Recycled Concrete

\section{INTRODUCTION}

Urban and country development typically comes together with the buildings; most of the civil engineering work uses concrete as a primary material for the construction with large volumes. There are a large number of technological advancements in construction materials continuing. The concrete using today was made from many materials such as cement, coarse aggregate, fine aggregate, water, etc. Several mega and mini construction projects in Thailand, when these buildings have been used for a long period, they will cause concrete deterioration over time or when disaster comes. Another way, when constructing a new building replace of the old one, it is vital to demolish the old building away. So, the structural concrete waste disposal from demolition is hardly possible and it becomes an environmental waste from the construction. It is seen that concrete waste from building demolition is increasing and hard to dispose of. Therefore, using a structural concrete material from the destroyed building replace of using natural coarse aggregates for new concrete will help reduce these problems well.

In Thailand, there was an experimental concrete strength comparison between natural coarse aggregates and 
recycled coarse aggregates. The outcome showed that the strength of concrete with coarse aggregate from structural concrete waste (recycled coarse aggregate) at 28 days has a higher value than a designed strength. And the tendency of an increase in recycled coarse aggregate concrete strength concerning the age of concrete has a similar pattern to natural coarse aggregate concrete, but its strength is by an average $18.5 \%$ lower. And the strength of recycled aggregate concrete results varies in line with the strength of concrete waste with the old structure as it was illustrated in the research [1] and in accordance with [2] the tendency of a development of strength, shear force, and strain at the concrete recycle's ultimate which is similar to the natural concrete. The strength and tensile strength of concrete using recycled concrete replace of coarse aggregates are dependent on the concrete mix proportion. Generally, the recycled concrete strength is less than normal concrete for $10-25 \%$ [3] following the research of [4]. To sum up, coarse aggregate from crushing the old concrete can be used in the replace of the natural coarse aggregate to mix and make concrete. Nevertheless, replacing the natural rock with old concrete waste from the digestion is needed to be considered in terms of manufacturing cost, construction cost, and environmental worthiness. [5][6].

In the United Kingdom (UK), it has been found that more than 50 percent of landfill waste comes from construction [7] and about 70 million tons comes from construction and demolition (C\&D) every year [8]. While in the United States of America (USA), it has been found that 29 percent of solid waste comes from construction work [9]. Whilst in Hong Kong, it also has been found that solid waste from construction work is as high as 38 percent of waste [10]. Moreover, in the sampling waste collected from construction sites, $75 \%$ has been found as concrete. Therefore, to benefit from waste or construction waste, methods must be found for making it into reusable material.

"Recycle" means taking previous primary materials and changing them such that they become secondary raw materials for making other products [11]. The Royal Institute defines "recycle" as "processing used materials to become new products which may be the same products or new products. This is to reduce the need to dispose of materials, which may yet still provide benefits. The aim is to reduce the wastage of raw materials and to reduce energy use, pollution, and waste. Glass, metal, paper, and other materials can be recycled." Unused materials going to waste can become reusable new materials. The meanings of "recycle" and "reuse" differ, in much as "reuse" means "cleaning used materials and reusing them more than once, such as plastic bags and glass bottles" [12]. "To reuse" is to repeatedly use without any change in form. Materials that can be reused are glass, glass bottles, paper, plastic, metal, iron, bronze, aluminum, asphalt, and others. Materials that cannot be reused are a wet waste, the residue of organic matter and radioactive substances.

Using recycled in $C \& D$ to replace coarse aggregate in concrete can be said as a form of recycling concrete. The Federal Republic of Germany first started using recycled concrete after World War Two to manage the rubble of concrete accumulated from the demolition or destruction of buildings, roads, airports, bridges, and others [13]. In Hong Kong, the government widely encourages the recycling of $C \& D$ materials taken from construction work and managing construction waste.

\section{OBJECTIVES}

The objectives of this research are to study how to application structural concrete which was destroyed replace of coarse aggregate with different strengths, to study the impact of air curing and chemical compound curing per recycled concrete strength which had the destroyed structural concrete waste mixed with different degrees replacing natural coarse aggregate, and to study the recycled aggregate concrete which is able to design concrete mixture and adapt it for concrete works regarding the Building Control Law and Construction Standards.

\section{RESEARCH METHODOLOGY}

This research brought old structural concrete waste to replace of natural coarse aggregate by comparing the strength between old structural concrete waste from different strengths and natural coarse aggregate. Comparing air curing and chemical compound curing method by testing at the concrete laboratory with 480 examples, comparing the strength of concrete $100 \%$ recycled coarse aggregate. The strength development from concrete curing by using the mathematics principles to forecast the strength of recycled aggregate concrete with different levels of strength. Study the Building Control Law [14]. and Construction Standards [15] , [16], [17], [18] , [19], [20]. which is relevant to compression of concrete strength determination for designing concrete structure, including an interview with concrete professionals experts who are also experienced as civil engineers.

\section{RESULTS}

The result from concrete strength test with 480 examples according to American Standard; ASTM C 42/C 42M-03 [15], British Standard; BS 6543; [16], and Japanese Industrial Standards; JIS A 5308 [17]. The standard for concrete and reinforced concrete (2009). Department of Public Works and Town Planning, Standard no.1101-52. [18], Concrete and reinforced concrete standards of the Department of Rural Road [19], and The Engineering Institute of Thailand Under H.M. The King's Patronage [20]. Revealed that a chemical compound curing has the concrete strength development higher than an air curing, and this method can help design recycled concrete mix to obtain the concrete strength more than a regulated law. Moreover, concrete professional's opinion to agree on the implementation of destroying structural concrete replace of natural coarse aggregate.

According to the concrete strength test between recycled coarse aggregate and natural coarse aggregate, designing concrete mix with $23.50 \mathrm{MPa}$ at 28 days is most in line with the concrete strength development of natural coarse aggregated concrete, and its strength value has achieved the design objective regarding the strength. So, 
the prediction equation for replacing coarse aggregate concrete can be estimated, and be able to improve or test the reliability according to the standards in order to protect from the wrong use by law or the implementation in construction management [21].

Regarding the new recycled concrete strength test which uses destroyed structural concrete with 4 acknowledged strengths replacing the $100 \%$ natural coarse aggregate by designing $23.50 \mathrm{MPa}$ concrete mixes at 28 days. The result showed that destroyed structural concrete can be processed through digestion and size selection to replace of natural coarse aggregate. Thus, the tendency of a strength increase is like a natural coarse aggregate. Regarding the test result, the value of recycled coarse aggregate strength should be between 22.80 and $35.50 \mathrm{MPa}$ for replacing natural coarse aggregate with structural concrete waste which had its strength value to develop the appropriate strength by using chemical compounds curing that had a strength more than air curing.

That below is an exponential equation from formulating a new concrete strength prediction equation and adjustment by using data from old structural concrete strength which was destroyed (RCA)

\section{Air curing}

$y=14.05(e)^{0.015 x}$

Chemical Compound curing

$y=23.18(e)^{0.002 x}$

$y=$ the new concrete strength which uses destroyed structural concrete replace of $100 \%$ coarse aggregate, Cube, (MPa), and $x=$ the old structural concrete strength which was destroyed, Cube, (MPa)

According to the result, repeating test samples of concrete again to check the reliability of the compressive strength of concrete structure equation and adjust the equation to be more realistic by using old concrete structure in Bangkok which was known compressive strength to replace the $100 \%$ natural coarse aggregate so that the exponential equation adjust to ;

\section{Air curing}

$$
\begin{aligned}
& y=12.69(e)^{0.015 x} \\
& \text { Chemical Compound curing } \\
& y=20.49(e)^{0.002 x}
\end{aligned}
$$

According to the result, designing concrete mixes with its recycle concrete strength above the prescribed law can be done. Hence, it can be applied to some concrete works such as roads, temporary buildings, or small-sized buildings, etc. with the required quality control. However, it is still not suitable for high-rise or large-sized buildings.

Concerning an in-depth interview with experienced engineers who have exposure to concrete and related laws, it is shown that

-The service life of a building depends on usability and maintenance; it should not be determined by a certain amount of years.

- Ministerial Regulation No. 6 [22] Regulations of the compressive strength are the important thing for structural concrete implementation because the strength is one of an important quality indicator for concrete and it is related to other parameters for structural concrete design.

According to the recycled concrete strength test, it can be developed to have concrete strength more than the minimum that the Building Control Law regulated. Besides, recycled concrete can be applied for concrete work as well.

The standard for a reinforced concrete building is important and it is necessary to have a quality control under the Engineering Institute of Thailand's standard for implementing recycled concrete replace of natural coarse aggregate.

Reusing concrete waste is suggested, but the right methods and processes regarding academic principles must be provided to ensure the structure strength.

Reusing structural concrete waste replace of natural coarse aggregate will help reduce the environmental impact, decrease waste landfills, decline natural rock explosion, lessen noise or dust pollution, etc.

The improvement guidelines for the building control law and standards of the recycled concrete act can be divided into 2 issues; (1) a building control law about concrete strength, regarding the ministerial regulations; it was a minimum strength for concrete building design and this is suitable enough. For recycled concrete, the maximum strength used for concrete structure should be identified, as well as the type of structures that are applicable for recycled aggregate concrete such as rural roads, less than a 2-story concrete building, etc. Furthermore, it is required to configure the parameters related to recycled aggregate such as water absorption rate, the ability of fresh concrete, the mixed size of recycled aggregate, the durability of recycled aggregate, etc. (2) Recycled aggregate concrete standards, there are 5 important issues; recycled concrete mixture proportion, mixture selection criteria, concrete evaluation criteria between recycled aggregate concrete and natural aggregate concrete, recycled aggregate concrete mixing technique which is needed to be standardized in terms of mixing sequence, mixing time, and the duration of concrete erection, and the recycled aggregate concrete test. The industry standard should be adapted in terms of quality, sample collection, and the deviation of a specimen.

\section{CONCLUSION}

The research revealed that the strength comparison between the natural coarse aggregated concrete and recycled concrete, it tends to have a strength increase similar to natural coarse aggregated concrete, but its strength value is less than natural coarse aggregated concrete. Chemical compound curing has developed the recycled concrete strength more than air curing method; it is able to design a recycled concrete mixture to obtain concrete strength higher than the minimum regulated by building control law, using the mathematical principles to find the relationship between new concrete strength and structural concrete waste strength which is used replace of natural coarse aggregates, together with opinions of concrete professionals' experts and civil engineers. They agree on the application of destroying structural concrete 
replacing coarse aggregate under the Building Control Law and Construction Standards. There are some issues to place importance on; (1) the building control law about concrete strength for use, and (2) a recycle aggregate concrete that requires quality control for use. If you require any further more information, please feel free to explore the research [23]. Therefore, an application of recycled structural concrete replaces of coarse aggregate will help reduce pollution from concrete waste. That is hard to dispose of, reduce the environmental impact of having a value-added on the concrete waste by replacing the natural coarse aggregate. Eventually, it is beneficial to national development continually.

\section{REFERENCES}

[1] Punkorn Cheewawutwatanawit, Waranon Kongsong, Seree Tuprakay, Sathian Charoenrian, Boontham Harnphanich, and Chaiwat Pooworakulchai. (2019). A Comparison of the Compressive Strength of Concrete between Natural Coarse Aggregate and Recycled Coarse Aggregate. Published in International Journal of Civil Engineering and Technology (IJCIET), Volume 10, Issue 6, June 2019, 411-417, ISSN Print: 0976-6308 and ISSN Online: 0976-6316, Accepted June 10, 2019

[2] KhaldounRahal (2005). Mechanical properties of concrete with recycled coarse aggregate. Department of Civil Engineering, Kuwait University, Kuwait. Accept July 29, 2005. accessed from http://www.sciencedirect.com

[3] Sami W. Tabsh *, Akmal S. Abdelfatah (2008). Influence of recycled concrete aggregates on the strength properties of concrete. Department of Civil Engineering, American University of Sharjah, Sharjah, United Arab Emirate from www.elsevier.com/conbuildmat

[4] Prachak Khembuppha. A Study of Common Properties of Concrete Using Coarse Aggregate from Degraded Old Concrete with Different Compressive Strengths. Master Thesis of Civil Engineering Education, Graduate School, King Mongkut'sInstitute of Technology Thonburi, 2005.

[5] Surasak Phusantiphong. A Study of Degraded Concrete to Replace Concrete Aggregate. Master Thesis of Engineering in Civil Engineering Program, Graduate School, King Mongkut's Institute of Technology Thonburi, 2002.

[6] Vivian W.Y. Tam. (2007) Economic comparison of concrete recycling: A case study approach. Retrieved July 4, 2007, from http://www.sciencedirect.com

[7] Ferguson, N. Kermode, C.L. Nash, W.A.J. Sketch, R.P. Huxford (1995). Managing and minimizing construction waste: a practical guide, Institution of Civil Engineers (ICE), London.

[8] B.J. Sealey, P.S. Phillips, G.J. Hill (2011). Waste management issues for the UK ready- mixed concrete industry. Resources, Conservation and Recycling 32 (2001) 321-331.
[9] M.J. Rogoff, J.F. Williams. (1994), Approaches to implementing solid waste recycling facilities. Noyes, Park Ridge, NJ.

[10] Buildings Department. (2005). Use of recycled aggregates in concrete: practice notes for Authorized persons and registered structural engineers. Buildings Department, Hong Kong Special Administrative Region.

[11] Technical Terms and Definition of Waste by the Environmental Engineering Association of Thailand.

[12] The Royal Institute. The Royal Institute Dictionary.Bangkok Metropolis, 1999.

[13] Akash Rao, Kumar N. Jha, Sudhir Mishra. Use of aggregates from recycled construction and demolition waste in concrete, Department of CE, IIT Kanpur 208016, India, accepted May 24, 2006.

[14] Building Control Act, 1979, Building Control Act No. 2, 1992, Building Control Act No.3, 2000, Building Control Act No. 4 , 2007.

[15] American Society for Testing Materials. (2014). ASTM C33, Specifications for fine aggregates for Concrete.

[16] British Standard. (1985). BS 6543 Guide to Use of Industrial by Products and Waste Materials in Building and Civil Engineering, British Standards Institution

[17] Japanese Industrial Standards. (2009). JIS A 5308. Ready-mixed concrete. Japanese Standards Association.

[18] Standard for concrete and reinforced concrete. (2009). Department of Public Works and Town Planning, standard no. 1101-52

[19] Concrete and reinforced concrete standards of the Department of Rural Road. Office Analysis, research, and development Department of Rural Roads. 2002.

[20] The Engineering Institute of Thailand Under H.M. The King's Patronage. (1997). Standard Specification Materials and construction of concrete structures

[21] W. Kongsong and C. Pooworakulchai. Improving for Construction Contract Management of Government Construction Projects. International Journal of Civil Engineering and Technology (IJCIET) Volume 9, Issue7, July 2018, pp. 253-260, Article ID: IJCIET 0907026

[22] Ministerial Regulation No. 6 (1984). Issued under the Building Control Act B.E. 2522

[23] Punkorn Cheewawutwatanawit. Application of Recycled Structure Concrete instead of Coarse Aggregate in accordance with the Building Control Laws and Construction Standards. A Ph.D. Dissertation for the Doctor of Philosophy in Engineering Law and Inspection Program, Faculty of Engineering, Ramkhamhaeng University. 2019. 